\title{
Geodemographics as a tool for targeting neighbourhoods in public health campaigns
}

\author{
Jakob Petersen • Maurizio Gibin • Paul Longley • \\ Pablo Mateos $\cdot$ Philip Atkinson • David Ashby
}

Received: 11 April 2009/Accepted: 1 April 2010/Published online: 5 May 2010

(C) Springer-Verlag 2010

\begin{abstract}
Geodemographics offers the prospects of integrating, modelling and mapping health care needs and other health indicators that are useful for targeting neighbourhoods in public health campaigns. Yet reports about this application domain has to date been sporadic. The purpose of this paper is to examine the potential of a bespoke geodemographic system for neighbourhood targeting in an inner city public health authority, Southwark Primary Care Trust, London. This system, the London Output Area Classification (LOAC), is compared to six other geodemographic systems from both governmental and commercial sources. The paper proposes two new indicators for assessing the performance of geodemographic systems for neighbourhood targeting based on local hospital demand data. The paper also analyses and discusses the utility of age- and sex standardisation of geodemographic profiles of health care demand.
\end{abstract}

Keywords Geodemographics - Neighbourhood targeting · Public health · Hospital episode statistics

JEL Classification $\mathrm{I} 18 \cdot \mathrm{N} 30$

\footnotetext{
J. Petersen · P. Longley $(\bowtie) \cdot$ P. Mateos

Department of Geography and Centre for Advanced Spatial Analysis, University College London, Gower Street, Bloomsbury WC1E 6BT, UK e-mail: plongley@geog.ucl.ac.uk

J. Petersen · M. Gibin · P. Atkinson

Southwark Primary Care Trust, 160 Tooley Street, London SE1 2TZ, UK

M. Gibin

School of Geography Birkbeck, University of London,

Malet Street, London WC1E 7HX, UK

D. Ashby

Dr Foster (Research) Ltd., 12 Smithfield Street, London EC1A 9LA, UK
} 


\section{Introduction}

The growing demand upon hospital and health care resources has followed a general trend across the economically developed world as a consequence of increasingly sedentary lifestyles, rising calorie supply per capita and ageing population (Wagner 1998; Bodenheimer et al. 2002; Department of Health 2004b; Saxena et al. 2006; Bleich et al. 2008). Hospital admissions are of prime concern because of their costs and social implications. Although hospital admissions only account for $19 \%$ of all contacts, they account for $58 \%$ of the NHS expenditure (Talbot-Smith and Pollock 2006). Patients with long-term or chronic diseases have the greatest needs: they represent only $5-10 \%$ of patients, but account for up to $55 \%$ of hospital bed days (Department of Health 2004b). Concerns about hospital admission rates have led to intense research into their upstream causes, and, especially, information regarding individual-level risk factors associated with long-term diseases is used for opportunistic 'healthy lifestyle' advice within the health care system as well as forming the basis for public health campaigns.

Public health campaigns are increasingly guided by the principles of social marketing, viz. balancing 'product, place, price and promotion' (Kotler and Zaltman 1971; Kotler et al. 2002). This paper focuses upon the use of geodemographics as a social marketing tool in order to create information about 'place' and to target local population with new public health campaigns.

The basic principles underpinning geodemographics, the analysis of people by where they live, have been comprehensively covered in recent publications (Sleight 2004; Harris et al. 2005), and this paper focuses on evaluating the utility of geodemographics in order to plan targeted public health campaigns within the jurisdiction of a local health authority, Southwark Primary Care Trust, London (UK). Geodemographics offers the prospects of integrating, modelling and mapping health care needs and other health indicators that are useful for the geographic targeting of such campaigns. Yet, the technology itself is not new, and sporadic reports about its potential remain just as boosterist in the recent past (Department of Health 2004a) as they were in 1985 (Speller and Hale 1985). One of the major obstacles has presumably been the lack of validation beyond the observation that it works sufficiently to be of interest for commercially driven, direct marketing (Vickers and Birkin 2007). The Office for National Statistics (ONS) has built publicly available geodemographic systems from Census data since the mid-1990s, but again reports of health applications have been sporadic (Openshaw 1995). The latest Census classification, the 2001 Census Output Area Classification (OAC), has been promoted in a more sustained manner, not least by appending it to the UK's geographical look-up table, National Statistics Postcode Directory, as well as several national surveys. The 'open source' approach of the OAC system also offers opportunities for evaluating the system or modifying it for new purposes (Singleton and Longley 2008).

In what follows, geo-coded hospital admission data from Hospital Episode Statistics (HES) are used to map and evaluate the potential of geodemographics as means of targeting in the setting of the inner city London Borough of Southwark. The paper uses in the first instance the official Census Output Area Classification 
(OAC) and compares it with a commercial geodemographic system, Mosaic UK, to illustrate strengths and limitations associated with the current geodemographic systems for public health applications. The paper then goes onto present a new open source geodemographic system for London based on Census data to compare seven competing geodemographic systems for targeting guided by hospital data and, finally, to explore the potential for age- and sex standardisation in a geodemographic analysis of hospital demand.

\section{Problem definition}

The ONS Output Area Classification (OAC) consists of a three-tier hierarchy with seven Supergroups subdivided into twenty-one Groups, again subdivided into a total of fifty-two Subgroups. Mapping OAC for Greater London reveals a pattern with large swathes of Inner London belonging to the single segment, the "Multicultural" Supergroup, and many other areas forming a mosaic of only sparsely represented segments (see Fig. 1). The OAC classification was devised to present a UK national geodemographic classification, yet Greater London's special status in the settlement system is apparent in the heavy concentration of neighbourhoods into just two of the seven Supergroups.

\section{Output Area Classification 2001}

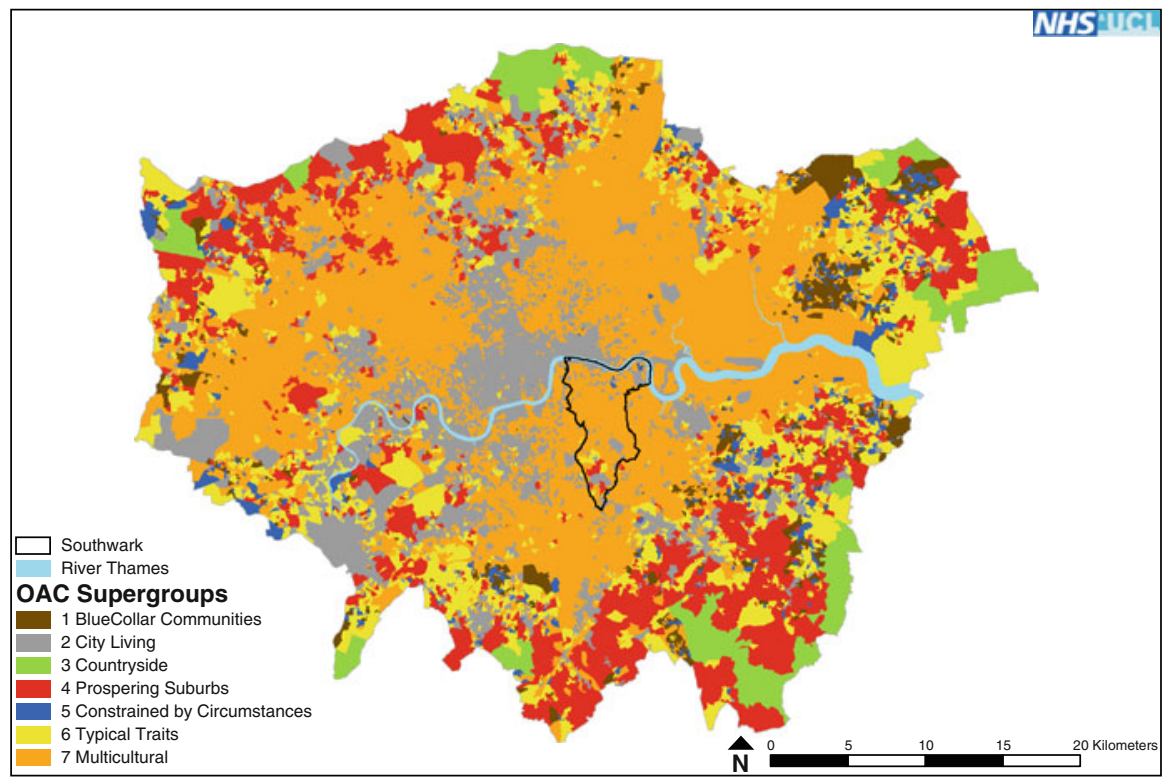

Data source: ONS 2006

Copyright $\odot 2006$ by J. Petersen and M. Gibin

Description: This map shows the Supergroups of the ONS area classification for London's over 24,000 Output Areas.

Fig. 1 Output Area Classification mapped for Greater London (OAC Supergroups) 
Table 1 Output Area Classification profile of patients registered in Southwark PCT, April 2006

\begin{tabular}{|c|c|c|c|c|}
\hline OAC supergroup & Freq. & Percent & $\begin{array}{l}\text { Mean } \\
\text { IMD } \\
\text { score }\end{array}$ & Typical census attributes \\
\hline 1 Blue collar communities & 7 & $<0.1$ & 28 & Terraced housing, renting publicly \\
\hline 2 City living & 35,450 & 11.1 & 25 & $\begin{array}{l}\text { Higher education qualifications, } \\
\text { single-person household (not } \\
\text { pensioner), born abroad, renting } \\
\text { privately, all flats }\end{array}$ \\
\hline 3 Countryside & 0 & 0 & - & $\begin{array}{l}2+\text { cars per household, working from } \\
\text { home, agriculture/fishing } \\
\text { employment, detached housing }\end{array}$ \\
\hline 4 Prospering suburbs & 2,266 & 0.7 & 17 & $\begin{array}{l}2+\text { cars per household, detached } \\
\text { housing }\end{array}$ \\
\hline $\begin{array}{l}5 \text { Constrained } \\
\text { by circumstances }\end{array}$ & 2,297 & 0.7 & 43 & All flats, renting publicly \\
\hline 6 Typical traits & 3,743 & 1.2 & 17 & Terraced housing \\
\hline 7 Multicultural & 275,488 & 86.3 & 37 & $\begin{array}{l}\text { Renting privately or publicly, } \\
\text { commuting to work on public } \\
\text { transport, all flats, born abroad, } \\
\text { South Asian or Black ethnic } \\
\text { background }\end{array}$ \\
\hline Total & 319,251 & 100.0 & 36 & \\
\hline
\end{tabular}

Sources: ONS, Indices of Multiple Deprivation (IMD) 2004 score (Noble et al. 2004)

The 'Multicultural' Supergroup is very dominant in Inner London, and indeed this neighbourhood Group accounts for some $86 \%$ of the 319,000 patients ${ }^{1}$ registered in Southwark (Table 1). The dominance of a single segment continues in the Group classification-one tier down from Supergroups. The majority of patients in Southwark reside in "Afro-Caribbean Communities". Segmentation with the finest and third tier segments, the Subgroups, still reveals that $44 \%$ of patients reside in just one unnamed Subgroup (data not shown).

A similar picture repeats itself with commercial postcode level geodemographic systems such as Experian's (Nottingham, UK) Mosaic UK (Table 2). Although this system exhibit greater differentiation of neighbourhoods, the majority of Groups account for fewer than $1 \%$ of patients and the classification is dominated by a single very large neighbourhood segment with $49 \%$ of all patients, the "Welfare Borderline" Group (Table 2), and 48\% in the second tier, "Metro-Multiculture" segment (data not shown).

The lack of specificity in these classifications makes them less suitable for targeted interventions, and this is the prime motivation for modifying the existing Census classification, OAC. The problem of specificity will in the following be discussed in a more general context in order to identify particular shortcomings that a modified version of the Census classification should address.

\footnotetext{
${ }^{1}$ A patient is here defined as anyone currently registered with a GP practice in the borough.
} 
Table 2 Mosaic UK profile of patients registered in Southwark PCT, April 2006

\begin{tabular}{|c|c|c|c|c|}
\hline Mosaic UK Group & Freq. & Percent & $\begin{array}{l}\text { Mean } \\
\text { IMD } \\
\text { score }\end{array}$ & Description \\
\hline A. Symbols of success & 13,276 & 4.2 & 19 & $\begin{array}{l}\text { People with rewarding careers who live in } \\
\text { sought after locations, affording luxuries and } \\
\text { premium quality products }\end{array}$ \\
\hline B. Happy families & 1,162 & 0.4 & 39 & $\begin{array}{l}\text { Families with focus on career and home, mostly } \\
\text { younger age groups now raising children }\end{array}$ \\
\hline C. Suburban comfort & 2,885 & 0.9 & 22 & $\begin{array}{l}\text { Families who are successfully established in } \\
\text { comfortable, mature homes. Children are } \\
\text { growing up and finances are easier }\end{array}$ \\
\hline D. Ties of community & 29,251 & 9.2 & 35 & $\begin{array}{l}\text { People living in close-knit inner city and } \\
\text { manufacturing town communities, responsible } \\
\text { workers with unsophisticated tastes }\end{array}$ \\
\hline E. Urban intelligence & 104,026 & 32.6 & 30 & $\begin{array}{l}\text { Young, single and mostly well educated, these } \\
\text { people are cosmopolitan in tastes and liberal in } \\
\text { attitudes }\end{array}$ \\
\hline F. Welfare borderline & 156,554 & 49.0 & 42 & $\begin{array}{l}\text { People who are struggling to achieve rewards } \\
\text { and are mostly reliant on the council for } \\
\text { accommodation and benefits }\end{array}$ \\
\hline G. Municipal dependency & 372 & 0.1 & 44 & $\begin{array}{l}\text { Families on lower incomes who often live in } \\
\text { large council estates where there is little owner } \\
\text { occupation }\end{array}$ \\
\hline H. Blue collar enterprise & 2,327 & 0.7 & 39 & $\begin{array}{l}\text { People who though not well educated are } \\
\text { practical and enterprising and may well have } \\
\text { exercised their right to buy }\end{array}$ \\
\hline I. Twilight subsistence & 3,593 & 1.1 & 39 & $\begin{array}{l}\text { Elderly people subsisting on meagre incomes in } \\
\text { council accommodation }\end{array}$ \\
\hline J. Grey perspectives & 2,416 & 0.8 & 21 & $\begin{array}{l}\text { Independent pensioners living in their own } \\
\text { homes who are relatively active in their } \\
\text { lifestyles }\end{array}$ \\
\hline K. Rural isolation & 0 & 0.0 & - & $\begin{array}{l}\text { People living deep in the countryside in small } \\
\text { communities little influenced by influx of } \\
\text { urban commuters }\end{array}$ \\
\hline L. Unclassified & 3,389 & 1.1 & 34 & Unclassified localities \\
\hline Total & 319,251 & 100.0 & 36 & \\
\hline
\end{tabular}

Sources: ${ }^{\odot}$ Experian Ltd (Nottingham, UK), Indices of Multiple Deprivation (IMD) 2004 score (Noble et al. 2004)

First, most geodemographic systems are based on clustering of attribute variables with no acknowledgement of the relative geographical location of localities. As a consequence, they contain residual regional, or local, variation that may erode the usefulness of the construct per se, i.e. the regionality problem (Sleight 2004). Second, all national classifications tend to be represented regionally by one dominant neighbourhood type and a number of other types of exponentially falling representation, the fragment problem (Batty 2006). This causes problems for the robustness of the imputation of attribute values, where base population numbers are low. The fragment problem is exacerbated in health care applications because of the 
strong and ubiquitous age gradient generally observed to characterise healthassociated conditions. Place effects may hence be confounded by differences in population age structure alone. To avoid this classic problem in health geography, health outcomes are typically standardised by age and sex. These standardisations, however, require further stratification of base population numbers that in many cases are already very small (see e.g. Table 1).

The regionality cum fragment problem is in other words manifested in attempts to generalise attribute space in a national classification, whereas Inner London Boroughs are distinctly different from most other locations in the United Kingdom on a variety of demographic and socio-economic factors. Clustering techniques such as $k$-means search at random for the optimal position of a predetermined number of 'seeds', $k$, that minimises the distance each neighbourhood has to the nearest seed when ordinated into a multi-dimensional attribute space spanned by the clustering variables. This process is sensitive to two 'forces'; (a) proximity in attribute space; and (b) outliers. In the case of Inner London, localities appear to cluster together more by being different from everywhere else (outliers) than by being uniquely similar (proximity).

There seems to be two immediate solutions to this problem. First, to segment clusters further recursively. This is notably the most common route of creating differentiation in geodemographic systems (Sleight 2004; Harris et al. 2005). The problem with this type of procedure is that it, if anything exacerbates the fragment problem, i.e. it creates even greater heterogeneity in base population sizes. Another solution, which will be pursued here, is to create a regional classification. Hypothetically, a regional classification would achieve greater differentiation and more evenness in base population structure simply by narrowing the attribute space to contain data from this region only; in this case Greater London.

\section{Methods}

The Output Area Classification (OAC) is based on a selection of forty-one Census 2001 variables ranging from age to ethnicity, family structure, tenure, education, occupation, transportation, and health (Vickers and Birkin 2007; Table 3). Localities (Census Output Areas in Great Britain) were first divided into seven OAC Supergroups using the $k$-means clustering algorithm. The stopping rule for the generation of these Supergroups was guided by mean centroid distance, which is a statistic that decreases with increasing number of seeds, $k$. Abrupt changes in this statistic are taken to indicate a parsimonious number of clusters. The final number of clusters is also guided by a more pragmatic consideration, i.e. the fact that it inherently difficult for end users to differentiate between more than about seven classes when the classification is mapped (Callingham 2006).

In order to explore whether greater differentiation could be obtained for London neighbourhoods, the same Census variables were re-clustered according to the OAC methodology, but with three modifications to form an alternative regional classification, London Output Area Classification (LOAC hereinafter);

i. Data pertaining to the Greater London area only 
Table 3 Census clustering variables

Clustering variables from Census 2001 used in the OAC and LOAC classifications

Age 0-4

Age 5-14

Age 25-44

Age 45-64

Age 65+

Indian/Pakistani/Bangladeshi

Black African

Black Caribbean or Black Other

Born outside UK

Population density

Divorced

Single-person household (not pensioner)

Single-pensioner household (pensioner)

Lone parent household

Two adult no children

Households with non-dependent children

Rent (public)

Rent (private)

Terraced housing

Detached housing

All flats
No central heating

Rooms per household

People per room

HE qualifications

Routine/semi-routine occupation

$2+$ Car household

Public transport to work

Work from home

Standardised long-term illness ratio

Provide unpaid care

Students (full time)

Unemployed

Working part-time

Economically inactive looking after family Agriculture/fishing employment

Mining/quarrying/construction employment Manufacturing employment

Hotel and catering employment

Health/social work employment

Financial intermediation employment

Wholesale/retail employment

Source: Vickers and Birkin 2007

Fig. 2 Stopping rule applied in the creation of London Output Area Classification (LOAC). Bars: show Callinsky-Harabaz pseudo-F values on the left axis. Line: relative information loss (\%)

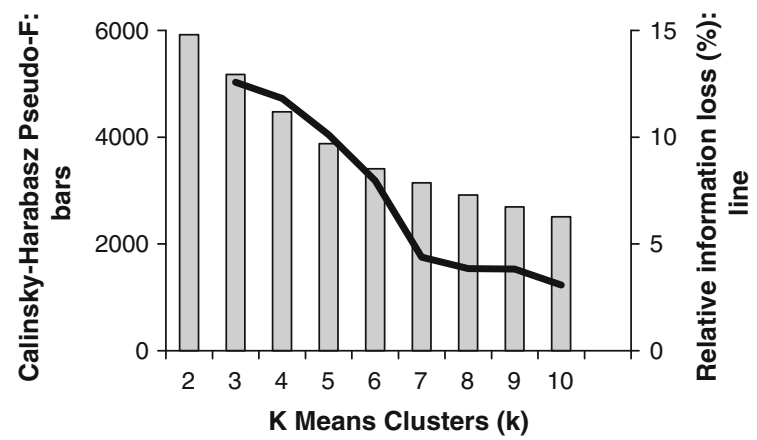

ii. All variables were logarithmically transformed and their range was standardised according to the Greater London distribution

iii. The number of clusters in each group and their subdivision into lower tiers was guided by the appearance of distinct thresholds in the ratio of within- versus between-cluster variability, in accordance with the Callinsky-Harabaz pseudo-F (Rabe-Hesketh and Everitt 2004). 


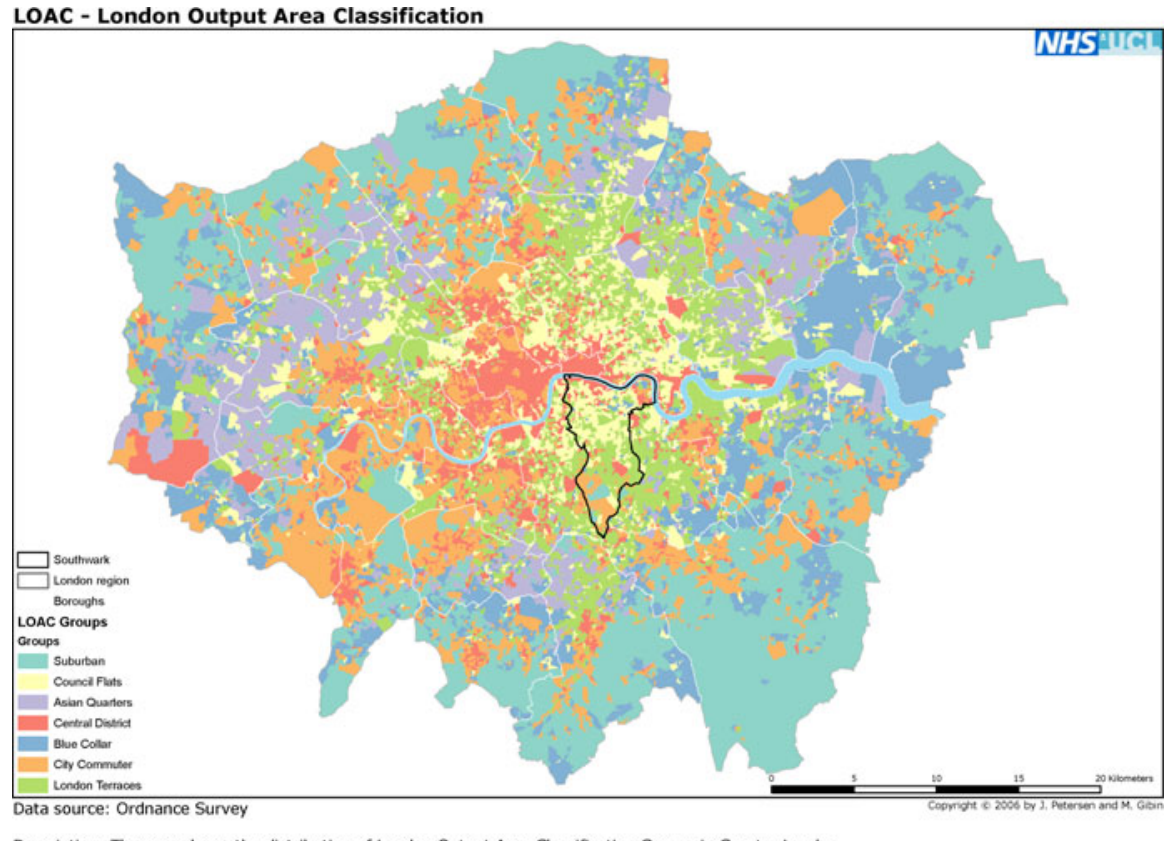

Description: The map shows the distribution of London Output Area Classification Groups in Greater London.

Fig. 3 London Output Area Classification (LOAC Groups)

Table 4 Geodemographic systems and neighbourhood differentiation

\begin{tabular}{llll}
\hline $\begin{array}{l}\text { Aggregation } \\
\text { level }\end{array}$ & $\begin{array}{l}\text { Neighbourhood } \\
\text { differentiation }\end{array}$ & $\begin{array}{l}\text { Number of segments } \\
\text { (Greater London) }\end{array}$ & Provider \\
\hline Postcode & Mosaic UK Type & 60 & Experian Ltd \\
& Acorn Type & 58 & CACI \\
& Health Acorn Type & 27 & CACI \\
Output area & OAC subgroups & 50 & ONS \\
& LOAC groups & 49 & Internal \\
Super output area & Index of multiple & 50 & Department of Communities \\
& deprivation & & and Local Government \\
& P2 branches & 38 & Beacon-Dodsworth \\
\hline
\end{tabular}

NB only segments represented in Greater London are included; this therefore excludes, for example, the Mosaic UK segment 'Rural isolation'

Permission to use the commercial systems were kindly obtained through academic licence agreements between Centre for Advanced Spatial Analysis, UCL, and Experian Ltd. (Nottingham), CACI (London) and Beacon-Dodsworth (Bishopthorpe)

Seven Supergroups were formed according to a distinct threshold in the information structure (Figs. 2, 3). Each LOAC Supergroup was further subdivided into forty-nine Groups following the same procedure. This makes the LOAC Group tier comparable to the OAC Subgroup tier with fifty subgroups represented in Greater London (Table 4). 
Table 5 Number of chronic disease admissions to hospital for residents of Greater London, Hospital Episode Statistics 2001-2004

Source: Department of Health

\begin{tabular}{lc}
\hline Chronic disease indicator (ICD10) & Admissions \\
\hline Angina pectoris (I20,I25) & 119,538 \\
Breast cancer (C50,D05) & 91,026 \\
Colorectal cancer (C17-C21) & 87,988 \\
All chest pain (R073-074,R101) & 85,861 \\
Back pain (M50-M54) & 55,713 \\
Mental health (F20-F48) & 54,180 \\
All arthroses (M15-M19) & 51,332 \\
Leukaemia (C91-C95) & 49,963 \\
COPD (J40-J44) & 49,751 \\
Stroke (I60-I69) & 43,930 \\
Lung cancer (C33-C34) & 43,774 \\
Asthma (J45-J46) & 36,573 \\
Congestive heart failure (I50) & 32,759 \\
Acute myocardial infarction (I21-I24) & 31,458 \\
Cholelithiasis (K80) & 29,145 \\
Traumatic brain injury (TBI) & 26,333 \\
Diabetes (E10-E14) & 25,508 \\
Skin cancer (C43-C44) & 23,663 \\
Epilepsy (G40-G41) & 19,087 \\
Prostate cancer (C61) & 16,669 \\
Cervical cancer (C53,D06) & 10,620 \\
Total & 984,871 \\
\hline
\end{tabular}

Hospital episodes data for Greater London, between 2001 and 2004, were obtained with age, sex, residential postcode, and primary diagnosis. Ethical approval was obtained through Bromley Local Research Ethical Committee and Patient Information Advisory Group (PIAG).

The diagnoses (ICD10 four-character system) were categorised into indicators according to the most commonly occurring chronic diseases (Office for National Statistics 2000; Department of Health 2004b, 2005); see Table 5.

In order to estimate the success of a geodemographic targeting strategy, a goal of reaching the top $20 \%$ of admissions was set for each of the diseases and compared to reaching the same goal by a geographic targeting strategy of using the data themselves to identify the minimum number of neighbourhoods that supply at least $20 \%$ of patients for each of the diseases. This follows the logic of a design used in medical diagnostics, i.e. comparing the overlap in frequencies of patients with a positive diagnosis using a high intervention test (the gold standard) with an alternative and usually cheaper low intervention test (Kirkwood and Sterne 2003). In this study, geographic targeting was used as gold standard and geodemographics, targeting based on 'area-type', as the alternative test.

The hospital admissions data were aggregated at three geographical levels (unit postcode, output area, and super output area) and labelled with the finest level codes of eight different geodemographic systems, e.g. the fifty subgroups in the Output 
Area Classification covering Greater London. The composite Index of Multiple Deprivation (IMD) was also included as a potential segmentation system (fifty quantiles according to IMD score in Greater London). Base population counts per unit postcode were derived from the 2001 Census and aggregated up to the different levels of geography using the National Statistics Postcode Directory (Office for National Statistics 2005).

The performance of the systems was evaluated by:

(1) Gini coefficients weighted by Census 2001 population counts. The Gini coefficient is an overall mathematical measure of heterogeneity (or inequality). Higher values of the Gini coefficient are associated with classifications that minimise the respective base population to target ratios. The Gini coefficient is, purportedly, the 'unofficial' industry standard for evaluating geodemographic systems (Callingham 2006).

(2) As an additional measure, two new performance indicators of targeting efficiency were created. They are both based on a ranking of geographic areas according to the crude rates for each disease indicator. The areas containing the top $20 \%$ of all frequencies for a given disease were flagged as 'targets'. These sets were treated as the diagnostic gold standard, and the same procedure was repeated with area types within each geodemographic system in order to create the alternative diagnostic sets.

(a) For each disease indicator and geodemographic system, diagnostic sensitivity was calculated as the percentage of gold standard admissions (admissions targeted in the geographic set) included in the alternative geodemographic target set. Each system is hence evaluated against other systems for geographic targeting at the same level of aggregation, e.g. a unit postcode system such as Mosaic UK is compared to a geographic targeting scheme ordering postcodes according to their crude disease rates and likewise with a system coded at Census Output Area level, and so on.

(b) The base population included in the geographic target of the top $20 \%$ of admissions (the gold standard) was divided by the number of admissions in the target for each disease to produce a numbers-to-target ratio. This was likewise repeated for the geodemographic target sets (the alternative standard).

\subsection{Age-standardised geodemographic profile}

Because LOAC as a regional classification has more even-sized segments than any of the other geodemographic systems, including OAC, it enables age standardisation of geodemographic risk profiles of, for example, London hospital admissions. Age standardisation is dependent upon detailed age-banded population estimates and many geodemographic systems are currently only delivered with total headcounts. LOAC is based on the Census geography and it is relatively simple to impute agebanded estimates for men and women from the Census itself or from the population estimates released by ONS annually at the Lower level Super Output Area (LSOA, a 
LSOA typically contains five Output Areas) level. In this study, ONS age-banded population estimates for the same years as the HES extract (2001-2004) were used with the twist of assigning populations from the coarser lower layer super output area (LSOA) level data to the finer output area level (OA) proportionally to the population share of each OA in their respective LSOAs in the 2001 Census. ONS use different age bands for women and men in this data product: 0-15 years, 1629 years, 30-44 years all for both sexes; and 45-59 years and 60+ years for women, and 45-64 year and 65+ year for men (for simplicity; only results for the analysis of the male population are reported here). Age-specific population-years-atrisk denominators were obtained by summing the population estimates over the 4 years of observation.

The age standardisation of hospital admission ratios, SARs, is derived following Kirkwood and Sterne (2003) with $i$ as age band, $p_{i}$ as population-at-risk and $\lambda_{i}$ as the age-specific rate per population-at-risk;

$$
\begin{gathered}
\text { SAR }=\frac{\text { Observed number of admissions }}{\text { Expected number of admissions }}=\frac{\sum a_{i}}{\sum \lambda_{i} p_{i}} \times 100 \\
\text { were the age-specific rates the same } \\
\text { as in the reference population }
\end{gathered}
$$

The data were analysed with an internal reference, i.e. the age-banded population of Greater London as reference. The equivalent crude admission ratios, CAR, were calculated following the same formula as for SAR only with a net crude admission rate based on headcounts instead. In order to highlight the potential effect of age standardising the geodemographic risk profile, crude and age-standardised ratios were compared in an attenuation index;

$$
\text { Attenuation index }=\frac{\mathrm{SAR}}{\mathrm{CAR}} \times 100
$$

If the age-standardised ratio is lower than the crude ratio, the effect of residing in a given neighbourhood type is — all other things being equal—explained by a higher proportion of elderly in that population (also known as effect attenuation). The opposite case would be expected where crude rates are lower due to a lower proportion of elderly - all else equal (also known as effect deattenuation).

\section{Results}

The regional Census neighbourhood classification had more evenly sized segments that were better differentiated on distinctive regional characteristics subsumed within the broader brush national classifications. Inspection of the mapped results of the OAC versus the LOAC clearly reveals that the inner city neighbourhoods are better differentiated using the LOAC (see Figs. 1, 3). In broad brush terms, this comparison revealed that the umbrella OAC "Multicultural" segment is replaced by three alternative LOAC segments, "2 Council Flats", "3 Asian Quarters," and "7 London Terraces". The main discriminatory variables were those related to tenure and ethnicity (Table 6). Comparing two LOAC Supergroups, "2 Council Flats" 
versus "4 Central District" across all clustering variables revealed marked differences in age structure, family structure, ethnic composition, education, and occupational variables (Fig. 4).

Using LOAC, patients in Southwark would be differentiated into neighbourhood groups with $52 \%$ of patients in the dominant group, "2 Council Flats" in the first tier of divisions (Table 6) and only $14 \%$ in the second unnamed Group in the second tier. Within OAC, the largest fragment occupied as already mentioned $86 \%$ in first tier ("Multicultural") (Table 1) and $80 \%$ in second tier. More importantly, the regional classification avoided the fragment problem experienced with other systems (Tables 1,2$)$.

The Gini coefficients showed the segmentations with two general commercial systems, Acorn and Mosaic, to be best optimised relative to the base populations

Table 6 London Output Area Classification profile of patients registered with Southwark PCT, April 2006

\begin{tabular}{lllll}
\hline LOAC & Freq. & Per & Mean & Typical census attributes \\
supergroup & & cent & IMD & \\
& & & score &
\end{tabular}

\begin{tabular}{lllll}
\hline Suburban & 3,346 & 1.1 & 16 & $\begin{array}{l}\text { Working age, white ethnic background, two-adult } \\
\text { households, large houses, higher education, } 2+\text { cars, } \\
\text { routine jobs and part-time employment }\end{array}$ \\
2 Council flats & $166,635 \quad 52.2 \quad 42 \quad \begin{array}{l}\text { Children and young adults, black ethnic minorities } \\
\text { and born abroad, divorces, single non-pensioner } \\
\text { households, lone parents, publicly rented } \\
\text { accommodation, apartment blocks, routine jobs, } \\
\end{array} \quad \begin{array}{l}\text { long-term illnesses, unemployed, part-time or } \\
\text { economically inactive looking after family }\end{array}$
\end{tabular}

3 Asian quarters $\quad 227 \quad 0.1 \quad 21 \quad$ Families, South Asian communities and people born abroad, two-adult households, terraced housing, routine jobs and part-time employment

4 Central district $\quad 28,297 \quad 8.9 \quad 25 \quad$ Young adults, born abroad, singles and two-adult households, renting privately, apartment blocks, higher education

5 Blue collar $\quad 6,721 \quad 2.1 \quad 38$

Families, white ethnic background, divorcees, lone parents, two-adult households, renting publicly, terraced housing, routine jobs and part-time employment, economically inactive looking after family

6 City commuter $\quad 19,889 \quad 6.2 \quad 20 \quad$ Working age, born abroad, single and two-adult households, apartment blocks, terraced housing, renting privately, large houses, higher education, $2+$ cars, part-time employment or economically inactive looking after family

7 London terraces $\quad 94,136 \quad 29.5 \quad 33$

Young adults, black ethnic background and born abroad, single and two-adult households, renting publicly, apartment blocks, terraced housing, higher education, routine jobs, long-term illnesses, parttime employment or economically inactive looking after family 


\section{London Output Area Classification}

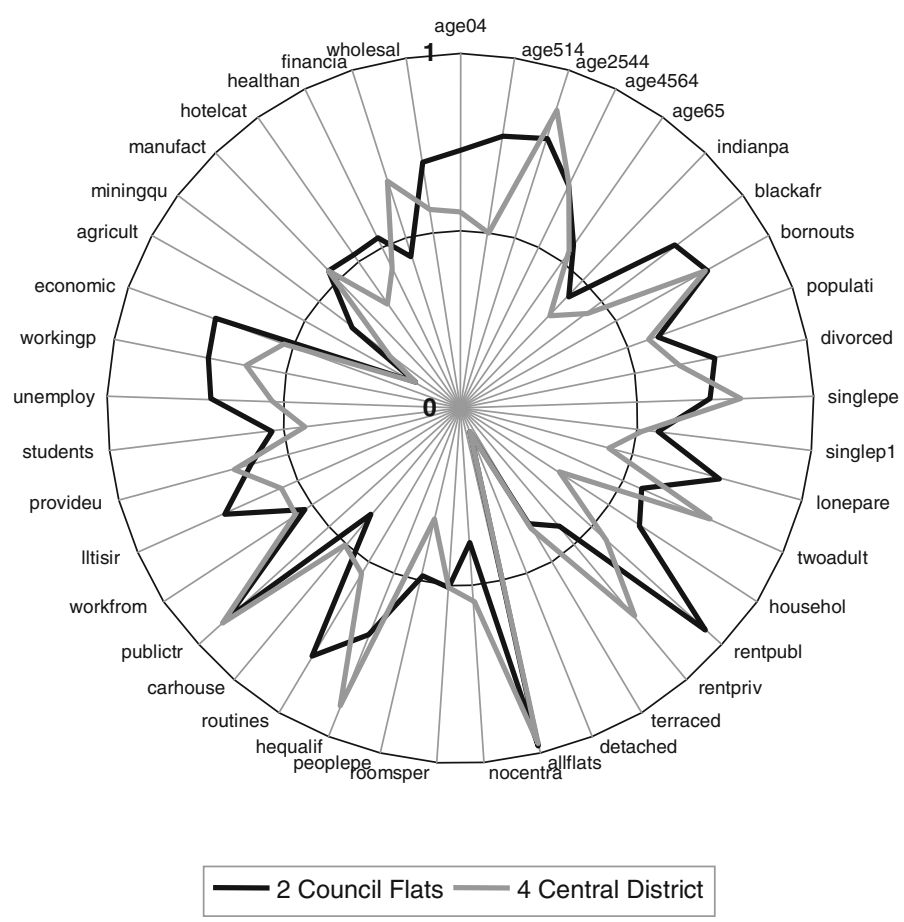

Fig. 4 Median Census attributes for two LOAC first tier clusters. Each attribute has been standardised to unity. For the full variable labels see Table 3

(Fig. 5). Comparable results was obtained with OAC (output area level); whilst the segmentation using the IMD performed the least well. Evaluating the systems relative to geographical targeting showed very low sensitivity overall. Postcode systems had the lowest sensitivity followed by output and super output area systems, respectively. The geodemographic strategies would in this study reach $20 \%$ of admissions, albeit not the same $20 \%$ as determined by the geographic targeting strategies. In fact, the proportional overlap, i.e. the sensitivity, could be as low as $20 \%$ and never exceeded 50\%. Strategies using geodemographic systems at postcode level would potentially provide a cheaper means of reaching the target population because of the relatively low base populations indicated by the lower number-to-target indicator values.

The potential confounding of age and sex in geodemographic risk profiles of health outcomes was demonstrated in different ways. Detailed age-banded denominators were created using ONS population estimates for the same time period. The differences in age structure were clearly demonstrated across the different LOAC Groups, as evidenced by the occurrence of greater numbers of elderly people in suburban neighbourhood types (Fig. 6). The age structure of patients of key long-term diseases was, as expected, strongly associated with age. Congestive heart failure was, for instance, almost exclusively associated with the 


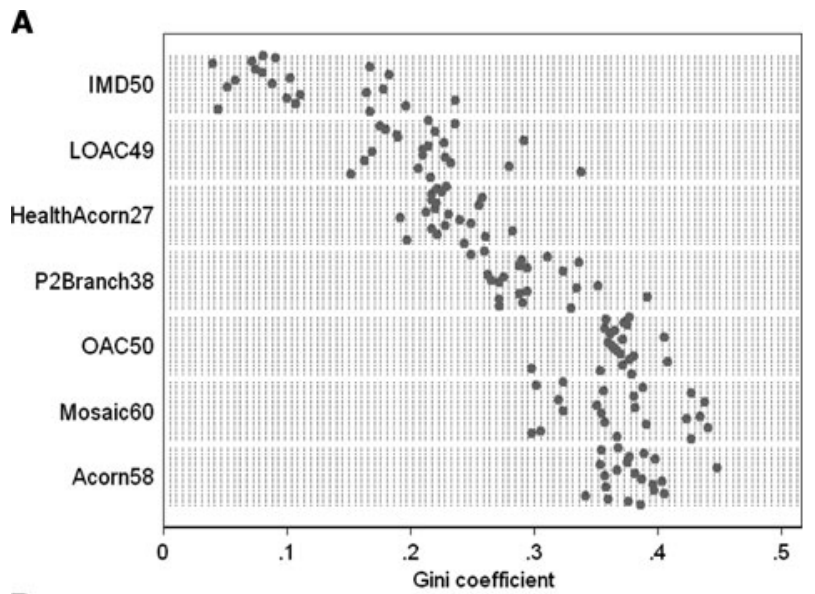

B
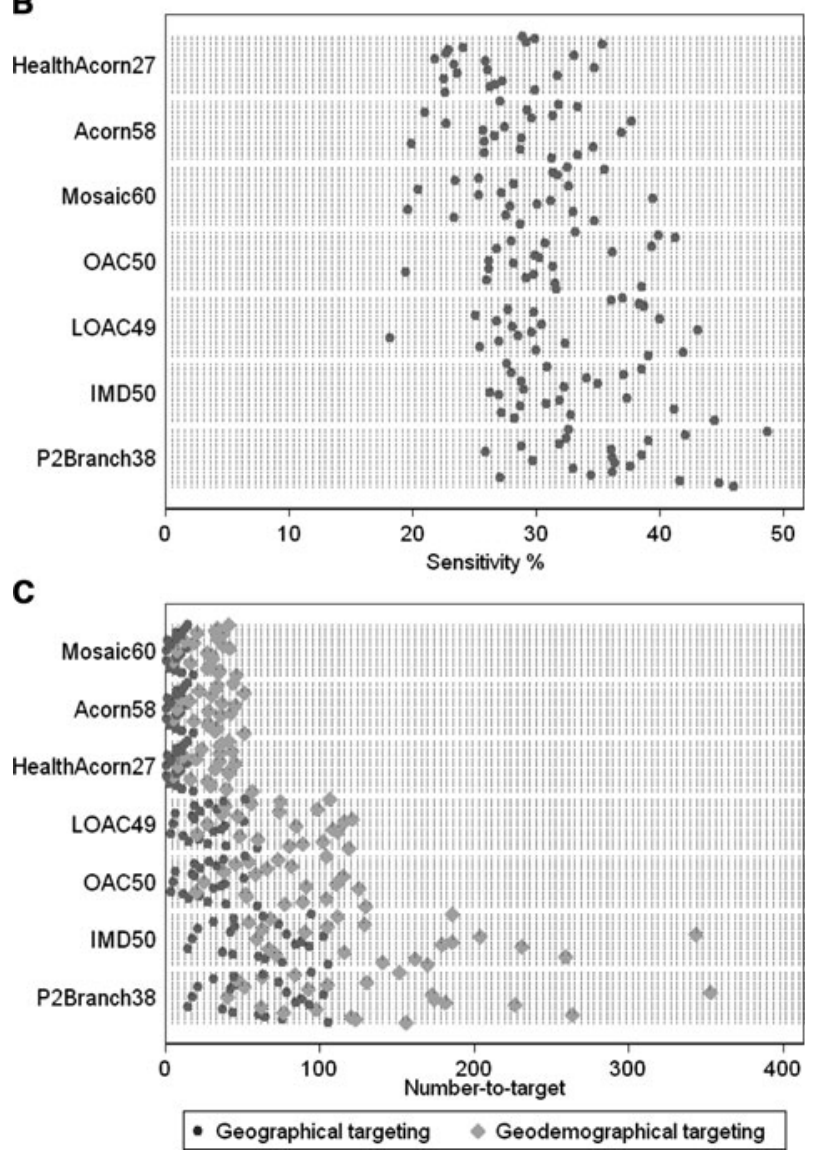

Fig. 5 a Gini coefficients for chronic diseases across seven different geodemographic systems in horizontal panels. b Sensitivity relative to geographic targeting as gold standard. c Number-to-target of same 


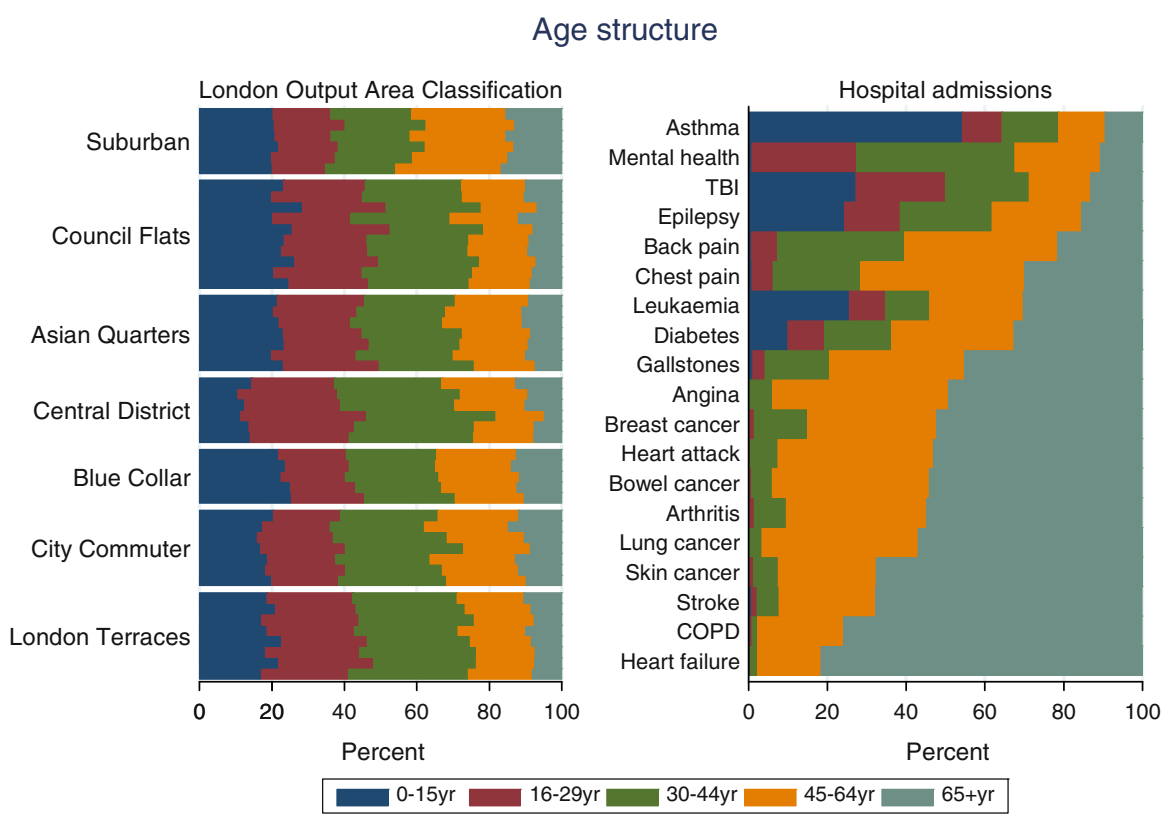

Fig. 6 Age structure in LOAC Groups and hospital admission data. Male population of Greater London 2001-2004

oldest age groups(only results for men are shown). Conversely, asthma predominantly affected children (Fig. 6).

In campaigns that are more concerned with upstream causes, age standardisation may thus be an important addition to geodemographic profiling. The usual crude profiles of angina, for example, showed that the "1 Suburban" Supergroup neighbourhood types had crude admission ratios above the regional average $(\mathrm{CAR}=100)$, although when standardised for age, they clearly fell below average $($ SAR $=100)($ Fig. 7$)$. The effect of a particular geodemographic neighbourhood type, as a container for lifestyle factors, was in this case confounded by a higher proportion of elderly; the geodemographic 'lifestyle effect' was in other words attenuated by age. Attenuation as well as de-attenuation effects were demonstrated across key long-term diseases for both women and men (Fig. 8). These effects were, as expected, strongest with diseases associated with either many or few elderly relative to other age groups.

\section{Discussion}

Besley and Kanbur (1990) propose that given scarce resources, geographical targeting should favour areas in order of need until the available budget is exhausted. Any targeted strategy based on aggregated data, however, opens up issues of inclusion and exclusion. A public health campaign strategy, for example, 


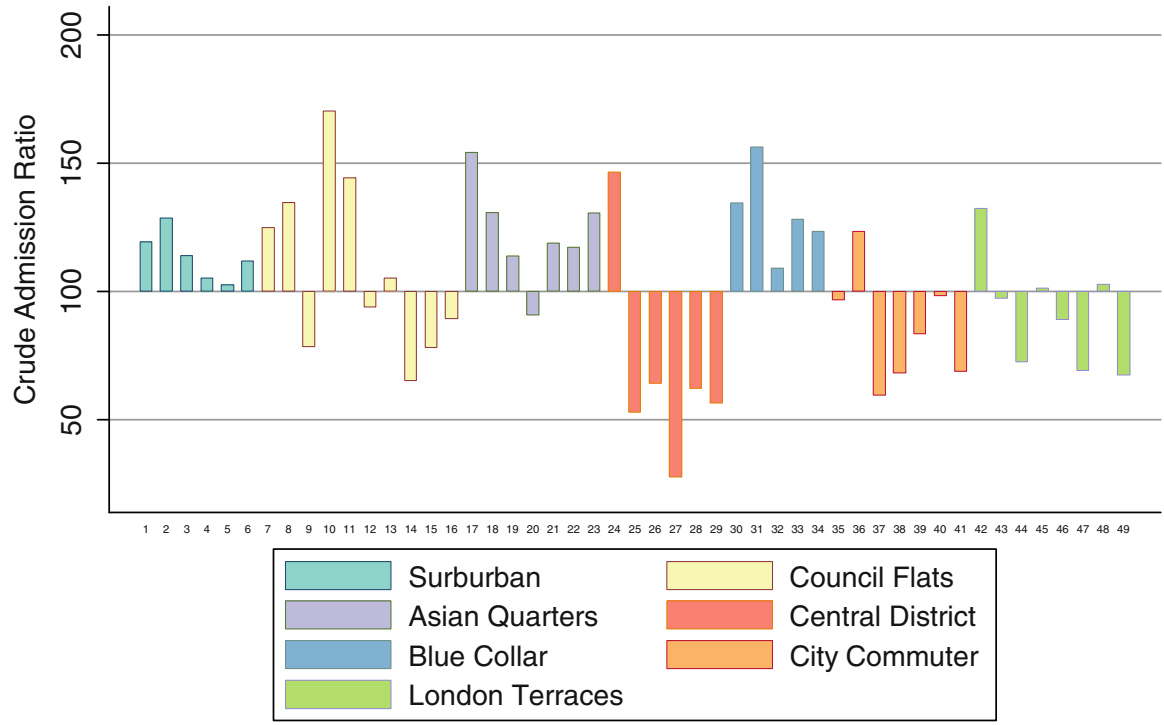

Male Admission for: Angina pectoris $(120,125)$

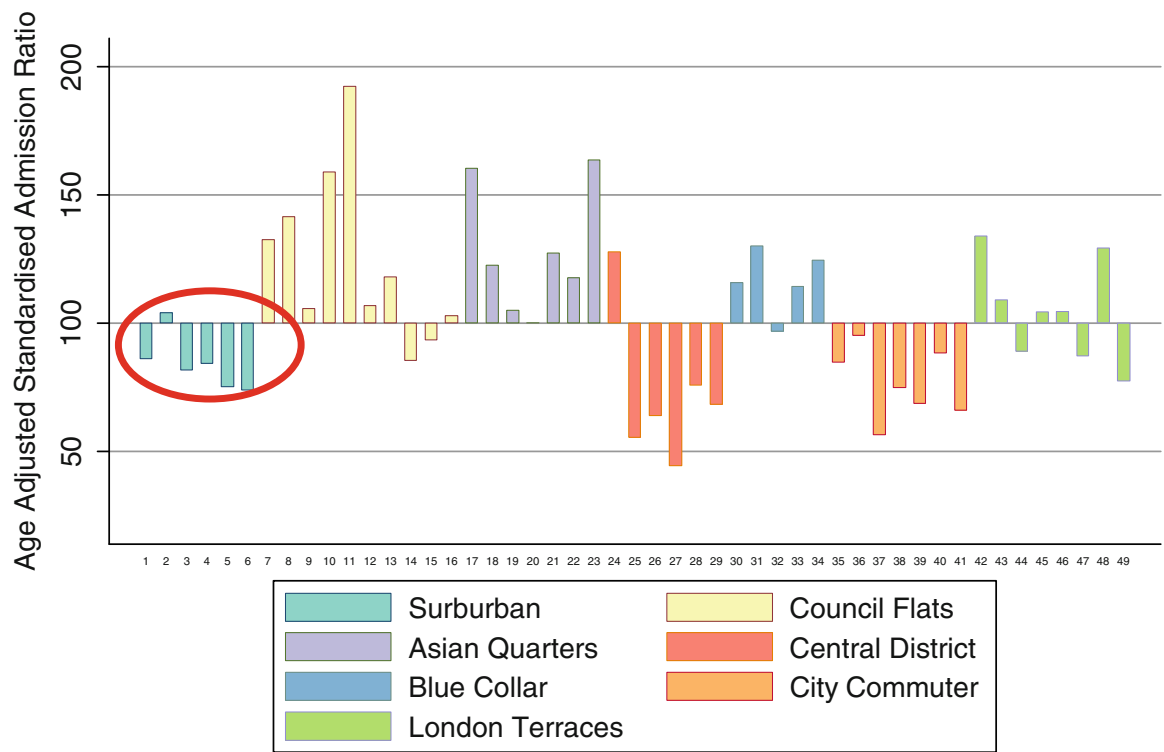

Male Admission for: Angina pectoris $(120,125)$

Fig. 7 Geodemographic profile (LOAC) for Angina pectoris hospital admissions. Top: Crude admission ratios. Bottom: Age-standardised ratios. NB Shift in the Suburban category with age standardisation

may include individuals who are not at risk for the health outcome it was designed to counter or ameliorate; i.e. the problem of inclusion. Conversely, there may be citizens with those exact needs that are excluded by the strategy simply by having the 'wrong' postcode, i.e. the exclusion problem. There seems no immediate 


\begin{tabular}{|c|c|c|c|c|c|c|c|c|c|c|c|c|c|c|c|c|c|c|c|c|}
\hline & $\begin{array}{l}0 \\
0 \\
0 \\
0 \\
\text { U } \\
0\end{array}$ & 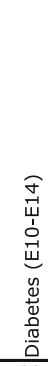 & 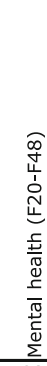 & 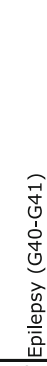 & 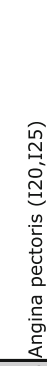 & 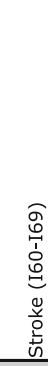 & 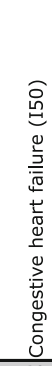 & 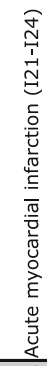 & 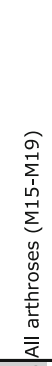 & 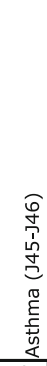 & 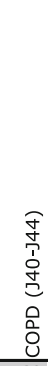 & 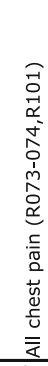 & 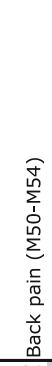 & 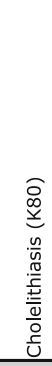 & 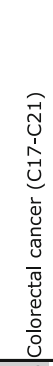 & 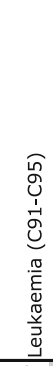 & 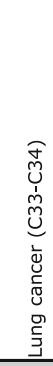 & 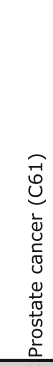 & 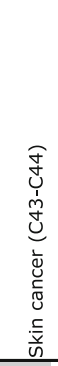 & 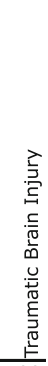 \\
\hline \multirow[t]{6}{*}{1} & 1 & 83 & 103 & 94 & 72 & 71 & 68 & 72 & 73 & 97 & 69 & 81 & 86 & 77 & 72 & 84 & 71 & 69 & 71 & $\frac{1}{99}$ \\
\hline & 2 & 89 & 103 & 96 & 81 & 81 & 80 & 81 & 82 & 98 & 80 & 88 & 92 & 85 & 81 & 90 & 80 & 79 & 81 & 99 \\
\hline & 3 & 82 & 104 & 93 & 72 & 71 & 68 & 72 & 72 & 96 & 69 & 81 & 86 & 77 & 71 & 84 & 70 & 68 & 71 & 99 \\
\hline & 4 & 88 & 104 & 95 & 80 & 80 & 78 & 80 & 81 & 95 & 79 & 87 & 91 & 84 & 80 & 89 & 79 & 78 & 80 & 99 \\
\hline & 5 & 84 & 103 & 94 & 73 & 72 & 70 & 73 & 74 & 98 & 70 & 82 & 87 & 78 & 73 & 85 & 72 & 70 & 73 & 99 \\
\hline & 6 & 78 & 104 & 92 & 66 & 65 & 63 & 66 & 67 & 97 & 63 & 76 & 83 & 72 & 66 & 81 & 65 & 63 & 65 & 98 \\
\hline \multirow[t]{10}{*}{2} & 7 & 103 & 104 & 100 & 106 & 105 & 104 & 106 & 105 & 94 & 104 & 106 & 106 & 105 & 106 & 100 & 106 & 105 & 105 & 99 \\
\hline & 8 & 103 & 99 & 101 & 105 & 102 & 101 & 104 & 104 & 101 & 101 & 104 & 104 & 103 & 104 & 102 & 104 & 102 & 102 & 99 \\
\hline & 9 & 116 & 110 & 101 & 135 & 137 & 143 & 135 & 135 & 86 & 141 & 124 & 120 & 129 & 136 & 105 & 137 & 142 & 138 & 97 \\
\hline & 10 & 96 & 100 & 99 & 93 & 90 & 88 & 93 & 92 & 100 & 89 & 97 & 98 & 94 & 92 & 96 & 92 & 89 & 90 & 99 \\
\hline & 11 & 115 & 106 & 103 & 133 & 129 & 130 & 132 & 130 & 91 & 131 & 124 & 121 & 126 & 132 & 107 & 133 & 132 & 130 & 97 \\
\hline & 12 & 107 & 103 & 101 & 114 & 112 & 113 & 113 & 113 & 95 & 113 & 110 & 108 & 111 & 114 & 103 & 114 & 114 & 113 & 99 \\
\hline & 13 & 106 & 102 & 101 & 112 & 110 & 110 & 112 & 111 & 96 & 111 & 109 & 108 & 109 & 112 & 103 & 112 & 111 & 110 & 99 \\
\hline & 14 & 114 & 106 & 101 & 131 & 133 & 137 & 131 & 130 & 90 & 136 & 120 & 116 & 125 & 132 & 106 & 133 & 137 & 133 & 98 \\
\hline & 15 & 110 & 99 & 103 & 119 & 120 & 122 & 119 & 118 & 101 & 122 & 111 & 107 & 114 & 120 & 108 & 121 & 123 & 120 & 100 \\
\hline & 16 & 107 & 105 & 100 & 115 & 115 & 116 & 115 & 115 & 92 & 116 & 111 & 109 & 112 & 115 & 102 & 116 & 116 & 115 & 98 \\
\hline \multirow[t]{7}{*}{3} & 17 & 102 & 102 & 100 & 104 & 107 & 108 & 105 & 105 & 98 & 107 & 103 & 103 & 105 & 105 & 101 & 105 & 107 & 107 & 99 \\
\hline & 18 & 97 & 101 & 99 & 94 & 94 & 93 & 94 & 94 & 99 & 93 & 97 & 99 & 96 & 94 & 97 & 93 & 93 & 94 & 99 \\
\hline & 19 & 96 & 103 & 98 & 92 & 93 & 93 & 93 & 93 & 96 & 93 & 95 & 97 & 95 & 93 & 95 & 92 & 93 & 93 & 99 \\
\hline & 20 & 105 & 103 & 100 & 110 & 113 & 116 & 111 & 111 & 95 & 115 & 107 & 105 & 109 & 111 & 102 & 112 & 115 & 113 & 99 \\
\hline & 21 & 104 & 104 & 100 & 107 & 108 & 109 & 107 & 107 & 94 & 108 & 106 & 106 & 107 & 107 & 100 & 107 & 108 & 108 & 98 \\
\hline & 22 & 100 & 100 & 100 & 100 & 101 & 102 & 101 & 101 & 101 & 102 & 100 & 100 & 101 & 101 & 101 & 101 & 102 & 101 & 100 \\
\hline & 23 & 113 & 103 & 103 & 125 & 128 & 132 & 126 & 125 & 96 & 131 & 117 & 113 & 121 & 126 & 107 & 127 & 131 & 128 & 99 \\
\hline \multirow[t]{6}{*}{4} & 24 & 93 & 94 & 100 & 87 & 84 & 82 & 87 & 86 & 113 & 83 & 90 & 92 & 88 & 86 & 98 & 86 & 83 & 84 & 102 \\
\hline & 25 & 103 & 89 & 106 & 105 & 105 & 107 & 105 & 104 & 128 & 107 & 99 & 95 & 101 & 105 & 112 & 106 & 107 & 105 & 105 \\
\hline & 26 & 100 & 91 & 104 & 100 & 100 & 101 & 100 & 99 & 121 & 01 & 97 & 95 & 98 & 100 & 108 & 100 & 101 & 00 & 104 \\
\hline & 27 & 127 & 88 & 113 & 161 & 169 & 188 & 161 & 158 & 129 & 184 & 125 & 112 & 139 & 163 & 135 & 170 & 186 & 168 & 105 \\
\hline & 28 & 111 & 91 & 107 & 122 & 124 & 129 & 122 & 121 & 119 & 129 & 109 & 103 & 115 & 123 & 117 & 125 & 129 & 124 & 104 \\
\hline & 29 & 110 & 91 & 106 & 121 & 123 & 128 & 120 & 120 & 118 & 127 & 108 & 102 & 113 & 121 & 116 & 123 & 128 & 123 & 104 \\
\hline \multirow[t]{5}{*}{5} & 30 & 92 & 103 & 96 & 86 & 85 & 83 & 86 & 86 & 95 & 83 & 92 & 95 & 89 & 86 & 92 & 85 & 83 & 85 & 99 \\
\hline & 31 & 90 & 106 & 95 & 8 & 8 & 77 & 83 & 83 & 92 & 78 & 91 & 95 & 86 & 82 & 88 & 81 & 78 & 80 & 97 \\
\hline & 32 & 93 & 103 & 97 & 89 & 89 & 88 & 89 & 89 & 95 & 88 & 93 & 95 & 91 & 89 & 93 & 88 & 88 & 89 & 99 \\
\hline & 33 & 94 & 108 & 96 & 89 & 8 & 85 & 89 & 89 & 90 & 85 & 95 & 99 & 92 & 89 & 90 & 88 & 85 & 87 & 97 \\
\hline & 34 & 100 & 107 & 98 & 101 & 100 & 99 & 101 & 101 & 90 & 99 & 103 & 104 & 102 & 101 & 96 & 100 & 99 & 100 & 98 \\
\hline \multirow[t]{7}{*}{6} & 35 & 93 & 101 & 97 & 88 & 87 & 86 & 88 & 88 & 99 & 86 & 92 & 93 & 90 & 88 & 94 & 87 & 86 & 87 & 100 \\
\hline & 36 & 86 & 98 & 96 & 77 & 75 & 72 & 77 & 77 & 104 & 73 & 84 & 88 & 80 & 76 & 89 & 76 & 73 & 75 & 100 \\
\hline & 37 & 97 & 94 & 101 & 95 & 96 & 97 & 95 & 95 & 110 & 97 & 94 & 93 & 95 & 95 & 102 & 95 & 97 & 96 & 103 \\
\hline & 38 & 105 & 95 & 103 & 110 & 112 & 115 & 110 & 110 & 109 & 114 & 103 & 99 & 106 & 110 & 108 & 111 & 114 & 112 & 103 \\
\hline & 39 & 90 & 99 & 97 & 82 & 8 & 81 & 83 & 83 & 102 & 81 & 88 & 91 & 85 & 82 & 92 & 82 & 81 & 82 & 100 \\
\hline & 40 & 94 & 98 & 99 & 90 & 85 & 87 & 90 & 90 & 104 & 88 & 93 & 95 & 92 & 90 & 96 & 89 & 88 & 89 & 100 \\
\hline & 41 & 98 & 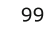 & 9 & 96 & & 101 & 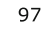 & 0 & 100 & & 93 & . & 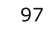 & י & 99 & 97 & 00 & 99 & 101 \\
\hline \multirow[t]{8}{*}{7} & 42 & 101 & 98 & 101 & 101 & 100 & 99 & 101 & 100 & 104 & 100 & 101 & 100 & 100 & 101 & 102 & 101 & 100 & 100 & 101 \\
\hline & 43 & 106 & 100 & 101 & 112 & 115 & 117 & 113 & 112 & 99 & 117 & 106 & 104 & 109 & 113 & 105 & 114 & 117 & 115 & 101 \\
\hline & 44 & 111 & 95 & 10 & 123 & & 120 & 122 & 122 & 109 & 128 & 111 & 106 & 116 & 123 & 113 & 125 & 129 & 124 & 102 \\
\hline & 45 & 102 & 98 & 101 & 103 & 103 & 103 & 103 & 103 & 104 & 103 & 102 & 101 & 102 & 103 & 103 & 103 & 103 & 103 & 101 \\
\hline & 46 & 109 & 102 & 102 & 118 & & 120 & 117 & 117 & 96 & 20 & 111 & 108 & 114 & 110 & 105 & 119 & 120 & 18 & 99 \\
\hline & 47 & 113 & 96 & 105 & 126 & 128 & 134 & 126 & 125 & 107 & 133 & 113 & 107 & 118 & 127 & 114 & 129 & 134 & 128 & 102 \\
\hline & 48 & 113 & 101 & 103 & 126 & 128 & 132 & 126 & 125 & 98 & 131 & 116 & 112 & 120 & 127 & 109 & 128 & 131 & 128 & 100 \\
\hline & 49 & 108 & 95 & 104 & 115 & 118 & 121 & 115 & 115 & 109 & 121 & 106 & 101 & 110 & 116 & 111 & 117 & 121 & 117 & 103 \\
\hline
\end{tabular}

$\leq 80$ Attenuation - Age-standardisation decreases admission ratio

$\geq 120$ Deattenuation - Age-standardisation increases admission ratio

Fig. 8 Effect of age standardisation of hospital admission ratios for key long-term diseases. Male patients in Greater London 2001-2004. Shading illustrates effects 20 percent below (light grey) or above the crude ratios (dark grey)

solution to this problem. Two different geodemographic systems would not suggest the same prediction for a local area simply due to differences in the methodology used to generalise complex, multivariable data. Different zonations as well as 
systems will invariably lead to different local estimations, as manifest in the Modifiable Area Unit Problem (Openshaw 1984). As a consequence, different areas and populations are selected and excluded in targeted campaigns.

The empirical analysis presented here suggested that, with respect to London, all of the geodemographic systems were relatively poor discriminators in comparison with geographic targeting (in this case: targeting areas rather than area types with the highest crude admission rates). This exemplifies exclusion problems: geodemographic allocation strategies would still reach $20 \%$ of admissions, albeit not the same $20 \%$ displaying the highest needs as determined by geographic targeting. The relatively high number-to-target ratios demonstrate the inclusion problems in both types of targeting, although geodemographic strategies would be more expensive to deploy, i.e. in terms of mail shots or other campaign means magnified by base population numbers.

The results of the diagnostic approach deployed here also suggest that, for these health indicators, it is the geographic order of aggregation (unit postcode, Output Area, or Super Output Area), more than the geodemographic classifications themselves, that is critical for the accuracy of targeting. This also questions whether Gini coefficients, however widely used, are in fact too sensitive to the huge withinregion variability in base population sizes. If this is indeed the case, their use becomes little more than a measure of population size heterogeneity rather than a measure of actual targeting 'efficiency'.

In this paper, two new performance indicators of targeting efficiency have been proposed in order to quantify these problems: sensitivity (the degree of overlap with a geographic targeting alternative) and the number-to-target (the sum of target and non-target population included in a campaign relative to the target). The (commercial and government) geodemographic systems evaluated in our London case study of hospital admissions proved to be rather insensitive to local conditions, because they were created using UK-wide Census and other data. In this way, there was only modest evidence of zone effects (in effect, the choice between classifications is not an important issue), whilst scale effects were clearly evident for the number-to-target criteria. Thus, our results confirm that scale of analysis does matter! In conclusion, the more fine-scale geodemographic systems were superior, not in sensitivity which in general was lower, but by including a lower number of non-target population (people not eligible for the campaign) in their target. The number-to-target is thus of relevance for the evaluation of campaigns intensified by mail shots, interviews or other methods involving direct contact to either households or individuals.

Geodemographic profiles of health outcomes revealed stark differences in the apparent health care needs of different populations. Geodemographics can in this way be said to project the same kinds of health inequality problems exposed by area deprivation scores or social class measures. Yet, compared to deprivation measures, geodemographics present a richer tapestry of potential factors that at least hypothetically can explain the emergence of health problems. Labels such as "social class IV" or "IMD score 27.9", on the other hand, seems less relevant to the interpretation of complex health information (Longley 2005). 
The techniques presented here demonstrate how geodemographics can be used to differentiate neighbourhoods on an array of demographic and socio-economic variables. It is important to note that the strength of geodemographics is to explore or describe, but not necessarily to explain particular health outcomes. Geodemographics does in other words nor replace carefully designed epidemiological studies aimed at oncovering individual-level risk factors. Geodemographics does, however, offer the social marketer a wealth of demographic information that can help define 'product, place, price, and promotion' for a given health campaign.

Age standardisation of geodemographic profiles is rare, possibly because it requires age-banded denominator data and robust estimates of risk across the different geodemographic segments, which again is hindered by small-number problems experienced when the current national geodemographic systems are applied locally, that is the fragment problem. The empirical example with geodemographic profiles of hospital admission data demonstrated that age-banded populations-at-risk denominators were achievable using current official population estimates. It was furthermore demonstrated that robust estimates of hospital admission risk were achievable when using a new, regional geodemographic system with more evenly sized base populations. The value of age standardisation was evident especially from geodemographic profiles of long-term diseases associated with elderly patients. The elderly with poorer health would for instance be 'hidden' if residing in areas with a younger-than-average age structure. Suburban neighbourhoods would by the same token 'qualify' for targeting, although the implied association with 'upstream' policy variables would be confounded by differences in the base population age structure alone.

This paper is not written with the aim of boosting geodemographics as a single solution, but to present it as a technique that can give valuable demographic context to many public sector applications, where social class and deprivation indices project similar inequalities, yet typically remain harder to interpret and operationalise in local planning. The modification of the national Output Area Classification for Greater London illustrates how bespoke geodemographic systems can assist in creating better differentiation on regional neighbourhood characteristics and, as of special interest to the health geography domain, enable analyses that are sensitive to the 'worst disease of all', age.

\section{References}

Batty M (2006) Rank clocks. Nature 444:592-596

Bleich S, Cutler D, Murray C, Adams A (2008) Why Is the developed world obese? Ann Rev Public Health 29:273-295

Bodenheimer T, Wagner H, Grumbach K (2002) Improving primary care for patients with chronic illness: the chronic care model, Part 2. JAMA 288(15):1909-1914

Callingham M (2006) Exploring the use and value of the ONS output area classification. http://www.rss. org.uk/rssadmin/uploads/577303_Callingham\%20Descriptions\%203\%20Oct\%202006.pdf. Accessed 3 April 2009

Department of Health (2004a) Choosing health: making healthier choices easier. Department of Health, London 
Department of Health (2004b) Improving chronic disease management. Department of Health, London

Department of Health (2005) National service framework for long-term conditions. Department of Health, London

Harris R, Sleight P, Webber R (2005) Geodemographics, GIS and neighbourhood targeting. Wiley, Chichester

Besley T, Kanbur, R (1990) The principles of targeting. Policy Res Working Paper Series 385

Kirkwood BR, Sterne JAC (2003) Essential medical statistics, 2nd edn. Blackwell, Malden

Kotler P, Zaltman G (1971) Social marketing: an approach to planned social change. J Mark 35(3):3-12

Kotler P, Roberto N, Lee N (2002) Social marketing: improving the quality of life. SAGE, London

Longley P (2005) A renaissance of geodemographics for public service delivery. Prog Hum Geogr 29(1):57-63

Noble M, Wright G, Dibben C, Smith G, McLennan D, Anttila C, Barnes H (2004) Indices of Deprivation 2004. Office of the Deputy Prime Minister, London

Office for National Statistics (2005) All fields postcode directory. London

Office for National Statistics (1998) Key health statistics from general practice 1998. Analyses of morbidity and treatment data, including time trends, England and Wales. Office for National Statistics, London

Openshaw S (1984) The modifiable areal unit problem. Concepts and techniques in modern geography. Geo Books, London

Openshaw S (1995) Geodemographic segmentation systems for screening health data. J Epidemiol Community Health 49:S34-S38

Rabe-Hesketh S, Everitt B (2004) A handbook of statistical analyses using Stata. Chapman \& Hall, CRC, Boca Raton

Saxena S, George J, Barber J, Fitzpatrick J, Majeed A (2006) Association of population and practice factors with potentially avoidable admission rates for chronic diseases in London: cross sectional analysis. J R Soc Med 99(2):81-89

Singleton A, Longley P (2008) Creating open source geodemographics-refining a national classification of Census Output Areas for applications in higher education. Pap Reg Sci 88(3):643-666

Sleight P (2004) Targeting customers. How to use geodemographics and lifestyle data in your business. WARC, Henley-on-Thames

Speller V, Hale D (1985) Making the most of your postcode. Health Serv J 28:53

Talbot-Smith A, Pollock AM (2006) The new NHS-a guide. Routledge, London

Vickers D, Birkin M (2007) Creating the UK National Statistics 2001 output areas classification. J R Stat Soc 170(2):379-403

Wagner H (1998) Chronic disease management: what will it take to improve care for chronic illness? Eff Clin Pract 1(1):2-4 